\title{
Formation and Evaluation of Au/ZnO Particles by a Spray Pyrolysis Method
}

\author{
Youngjun LEE $^{1 *}$, Toshiyuki FuJIMOTO², Shinya YAMANAKA², and Yoshikazu KugA ${ }^{3}$ \\ ${ }^{1}$ Division of Engineering, Muroran Institute of Technology, 27-1 Mizumoto-cho, Muroran, Hokkaido 050-8585, Japan \\ ${ }^{2}$ College of Environmental Technology, Muroran Institute of Technology, 27-1 Mizumoto-cho, Muroran, Hokkaido 050-8585, Japan \\ ${ }^{3}$ Muroran Institute of Technology, 27-1 Mizumoto-cho, Muroran, Hokkaido 050-8585, Japan
}

\begin{abstract}
ZnO} / \mathrm{Au}$ is expected to exhibit catalytic properties by absorbing ultraviolet and visible light because $\mathrm{ZnO}$ and $\mathrm{Au}$ nanoparticles can absorb ultraviolet and visible light, respectively. Doping studies on $\mathrm{Au}$ nanoparticles on $\mathrm{ZnO}(\mathrm{ZnO} / \mathrm{Au}$ ) have been conducted to expand the absorption wavelength range. This study generates $\mathrm{ZnO} / \mathrm{Au}$ particles by an ultrasonic spray pyrolysis method (USP). To prevent particle aggregation, Triton X-100, a non-ionic surfactant, is added, and its effects are examined. The generated $\mathrm{ZnO} / \mathrm{Au}$ particles are characterized using different methods. SEM reveals the particle size is several micrometers, while XRD analysis indicates that $\mathrm{ZnO}$ and a metallic Au crystalline are present. The TEM images of the particles show that the Au crystals are well dispersed in the inner and outer portions of $\mathrm{ZnO}$. UV-Vis spectroscopy confirms that the smaller the Au particle size, the higher the visible absorption peak near $400 \mathrm{~nm}$. Adding Triton X-100 shifts the absorption peak toward the longer wavelength side but improves the aggregation of Au particles.
\end{abstract}

\section{Introduction}

In developing countries, environmental pollution of organic cloth dyes and industrial wastewater is a very serious issue. It is generally treated using adsorption and chemical coagulation methods (Sauer et al., 2002; Wang et al., 1998; Matthews, 1991; Galindo et al., 2001). However, this may cause secondary pollution. The decomposition of organic pollutants by an oxidation treatment is a promising alternative (Fockedey and Van Lierde, 2002). Because photocatalysts are especially promising, various photocatalysts are being studied and produced. Oxide photocatalysts such as $\mathrm{SnO}_{2}, \mathrm{TiO}_{2}, \mathrm{WO}_{2}$, and $\mathrm{Fe}_{2} \mathrm{O}_{3}$ can effectively decompose organic pollutants under ultraviolet light irradiation. In recent years, $\mathrm{ZnO}$ has attracted much attention due to its physical and chemical stability. Since it has a high oxidation property, it should realize practical applications as a photodecomposition catalyst of organic pollutants. (Gouvea et al., 2000; Feng et al., 2016; Ebin et al., 2012; Georgekutty et al., 2008). It can be also used to remove volatile organic compounds (VOCs) coated on building materials.

Although $\mathrm{ZnO}$ is widely used as a photocatalyst, one drawback is that its catalytic properties are limited to the ultraviolet region due to its wide bandgap. When a noble metal crystal is doped into $\mathrm{ZnO}$, the excess electrons excited in $\mathrm{ZnO}$ are received by the noble metal crystal. Consequently, the oxidation characteristic may be improved (Georgekutty et al., 2008; Ardestani et al., 2014; Fallah-Shojaei et al., 2015). Metal nanoparticles have a localized surface plasmon resonance, which absorbs light in the visible region and induces a vivid color (Huang et al., 2010; Haes et al., 2004). Therefore, doping $\mathrm{Au}$ nanoparticles on particles of $\mathrm{ZnO}(\mathrm{ZnO} / \mathrm{Au})$ should improve the oxidation characteristics.

On the other hand, the photocatalytic activity is so large that the influence of external factors from the particles cannot be ignored. Ultrafine particles represent intermediate characteristics of molecules and bulk particles larger than single crystals. Consequently, they are attracting attention in various fields. The energy structure of semiconductor ultrafine particles significantly differs from bulk particles due to the quantum size effect. The bandgap increases as the particle size become smaller. Therefore, the reducing power of the photogenerated electrons and the oxidizing power of the holes become larger as the particle size decreases. A semiconductor ultrafine particle photocatalyst should exhibit a larger catalytic activity than in bulk particles (Henglein, 1989; Steigerwald and Brus, 1990; Weller, 1993).

Recently, Ebin et al. (2012) used an ultrasonic spray pyrolysis (USP) method to produce $\mathrm{ZnO}$. They measured the crystallite size and catalytic properties as functions of temperature. The USP method can generate particles continuously via a single process, where the temperature determines the particle size. In addition, the crystallite size can be controlled by changing the concentration of the raw material solution, and other elements can be doped by adding other materials (Wuled et al., 2000; Mizutani et al., 1986). This study aims to generate

Corresponding author: fjmt@mmm.muroran-it.ac.jp 
$\mathrm{ZnO} / \mathrm{Au}$ particles with wide spectra absorption region and high oxidative properties to realize high an effective photocatalytic reaction for organic pollutants by ultrasonic spray pyrolysis method.

\section{Experimental}

\subsection{Materials}

Zinc nitrate $\left(\mathrm{Zn}\left(\mathrm{NO}_{3}\right)_{2}\right)$, chloroauric acid $\left(\mathrm{HAuCl}_{4}\right)$, and Triton X-100 were purchased from Wako Pure Chemical Industries. All reagents were used as received without further purification. Water was distilled.

Table 1. Experimental conditions of $\mathrm{ZnO} / \mathrm{Au}$ nanocomposite particles generated via the USP method.

\begin{tabular}{|c|c|c|c|c|}
\hline \multirow{2}{*}{ No. } & \multicolumn{2}{|c|}{ Concentration $[\mathrm{wt} \%]$} & \multirow{2}{*}{$\begin{array}{l}\text { Triton } \\
{[\mathrm{wt} \%]}\end{array}$} & \multirow{2}{*}{$\frac{\mathrm{Au}(\mathrm{mol})}{\mathrm{ZnO}(\mathrm{mol})}$} \\
\hline & $\mathrm{Zn}\left(\mathrm{NO}_{3}\right)_{2}$ & $\mathrm{HAuCl}_{4}$ & & \\
\hline $\mathrm{Z} 0$ & \multirow{9}{*}{2.5} & - & - & - \\
\hline $\mathrm{Z1}$ & & 0.025 & \multirow{4}{*}{0} & 0.006 \\
\hline $\mathrm{Z} 2$ & & 0.05 & & 0.011 \\
\hline $\mathrm{Z3}$ & & 0.1 & & 0.022 \\
\hline $\mathrm{Z} 4$ & & 0.2 & & 0.045 \\
\hline T1 & & 0.025 & \multirow{4}{*}{0.25} & 0.006 \\
\hline $\mathrm{T} 2$ & & 0.05 & & 0.011 \\
\hline $\mathrm{T} 3$ & & 0.1 & & 0.022 \\
\hline T4 & & 0.2 & & 0.045 \\
\hline
\end{tabular}

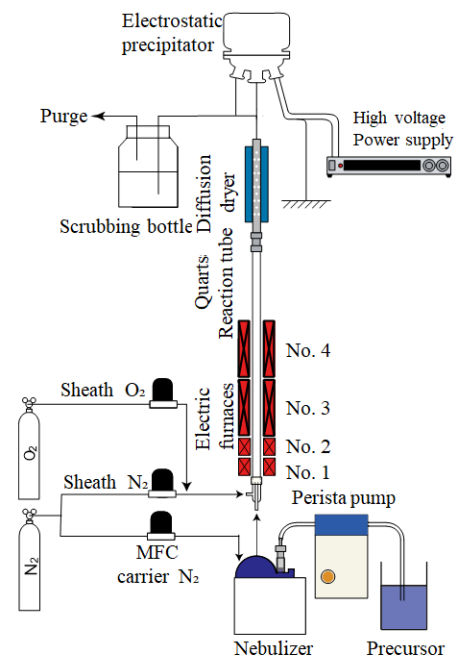

Figure 1. Schematic diagram of ultrasonic spray pyrolysis

\subsection{Preparation of $\mathrm{ZnO} / \mathrm{Au}$ nanocomposite particles}

$\mathrm{ZnO} / \mathrm{Au}$ nanocomposite particles were prepared by the USP method. Figure 1 schematically illustrates the apparatus for powder generation. The USP apparatus is composed of a nebulizer, electric furnaces, quartz reaction tube, diffusion dryer, and an electrostatic precipitator. A mixed solution of zinc nitrate and chloroauric acid was used as a starting material. The precursor solution was sprayed using a nebulizer (OMRON, NE-U17) with a resonance frequency of $1.7 \mathrm{MHz}$. The droplets were moved into the quartz reaction tube at a high temperature by air flow from the gas cylinder. The flow rates of the carrier gas and sheath gas were fixed at 1.0 and 0.5 SLM, respectively. The quartz reaction tube was placed inside electric furnaces with a temperature controller of $\pm 1^{\circ} \mathrm{C}$. The quartz reaction tube passed through four furnaces: two $80-\mathrm{mm}$ long preheating furnaces at $40^{\circ} \mathrm{C}$ (No. 1) and $70^{\circ} \mathrm{C}$ (No. 2) and two 290 -nm heating furnaces at $150^{\circ} \mathrm{C}$ (No. 3) and $1000^{\circ} \mathrm{C}$ (No. 4). The particles generated by decomposition of the starting material were dried by a water-cooling-type diffusion drier and collected in an electrostatic precipitator. Table 1 shows the experimental parameters to prepare $\mathrm{ZnO} / \mathrm{Au}$ nanoparticles and the experiment names $\mathrm{Z} 0-\mathrm{Z} 4$ and $\mathrm{T} 0-\mathrm{T} 4$, which indicate conditions with and without Triton X-100, respectively.

\subsection{Characterization}

X-ray diffraction (Rigaku, Multiflex) using $\mathrm{Cu} \mathrm{K} \alpha$ radiation was used to investigate the size and crystalline phase of the particles. The mean crystalline size of the particles was calculated using Scherrer's equation. The shape and size of the particles were investigated using a scanning electron microscope (SEM, JEOL JSM-6380A) and a transmission electron microscope (TEM, JEOL JEM-2100F). The obtained $\mathrm{ZnO} / \mathrm{Au}$ particles were dispersed in water, and the UV-Vis spectrum was measured using a spectrometer with an absorption wavelength of 300-800 nm (SIMAZU, UV-1800).

\section{Results and Discussion}

\subsection{Structural characteristics}

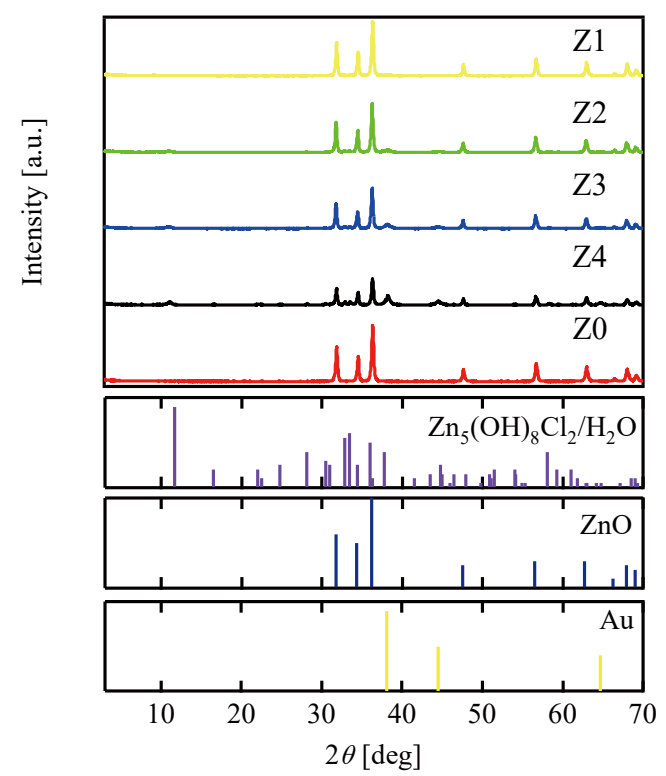

Figure 2. $\mathrm{XRD}$ patterns of $\mathrm{ZnO} / \mathrm{Au}$ particles obtained at different concentrations 


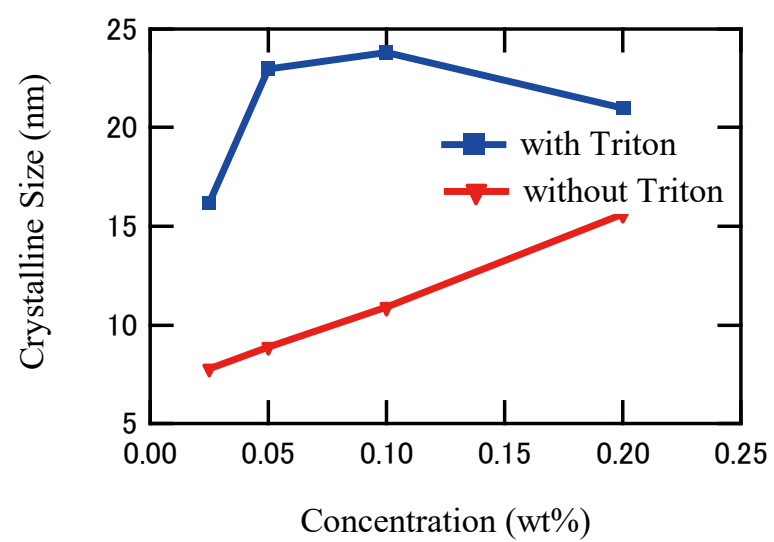

Figure 3. Crystallite size of $\mathrm{Au}$ calculated by Scherrer's equation.

Figure 2 shows the XRD pattern of the $\mathrm{ZnO} / \mathrm{Au}$ nanocomposite particles obtained without Triton X-100. All peaks of $\mathrm{ZnO}$ [(100), (002), (101), (102), (110), (103), (200) and (112)] are characteristic of the wurtzite (hexagonal) structure. In the $\mathrm{ZnO} / \mathrm{Au}$ nanocomposite particles with different $\mathrm{Zn} / \mathrm{Au}$ molar ratios, peaks of $\mathrm{ZnO}$ and $\mathrm{Au}$ appear, suggesting that $\mathrm{Au}$ is preserved in the metal form in the nanocomposites. The peaks (111), (200), and (220), which are characteristic of the fcc structure of $\mathrm{Au}$, decrease as the addition ratio of chloroauric acid decreases. Additionally, the peak of $\mathrm{Au}$ is not confirmed under the condition where the concentration of chloroauric acid (III) is $0.025 \mathrm{wt} \%$. The small peaks shown at $2 \theta=11^{\circ}$ are attributed to the residual products generated at low temperatures.
The crystallite sizes of the sample were calculated using Scherrer's equation. Figure 3 shows the crystallite size change under different conditions. The crystallite size of $\mathrm{Au}$ in the conditions $\mathrm{Z1}, \mathrm{Z2}, \mathrm{Z3}$, and $\mathrm{Z} 4$ are 7.8, 8.9, 10.9 and $15.6 \mathrm{~nm}$, respectively. This indicates that the crystallite size becomes smaller as the concentration of chloroauric acid (III) decreases. In addition, the crystallite size of $\mathrm{Au}$ in the T1, T2, T3, and T4 (with added Triton $\mathrm{X}-100)$ are 16.2, 23.0, 23.8 and $21.0 \mathrm{~nm}$, respectively. Adding Triton X-100 increases the crystallite size.

\subsection{Morphological characteristics}

Figure 4 shows the shape and size of the particles in the SEM image at different chloroauric acid (III) concentrations and Triton X-100 concentrations. Neither the chloroauric acid (III) $(0.025-0.2 \mathrm{wt} \%)$ nor Triton X100 induce morphological changes. Overall, the particles have hollow and filled structures, leading to an uneven surface. Rapid pyrolysis rates and high temperature drying result in hollow particles (Milosevic et al., 1993). These hollow particles realize a particle size larger than the theoretical particle size.

The average size of the sprayed droplets can be estimated as (Lang, 1962)

$$
D_{\text {droplet }}=0.34\left(\frac{8 \pi \gamma}{\rho f^{2}}\right)^{1 / 3}
$$
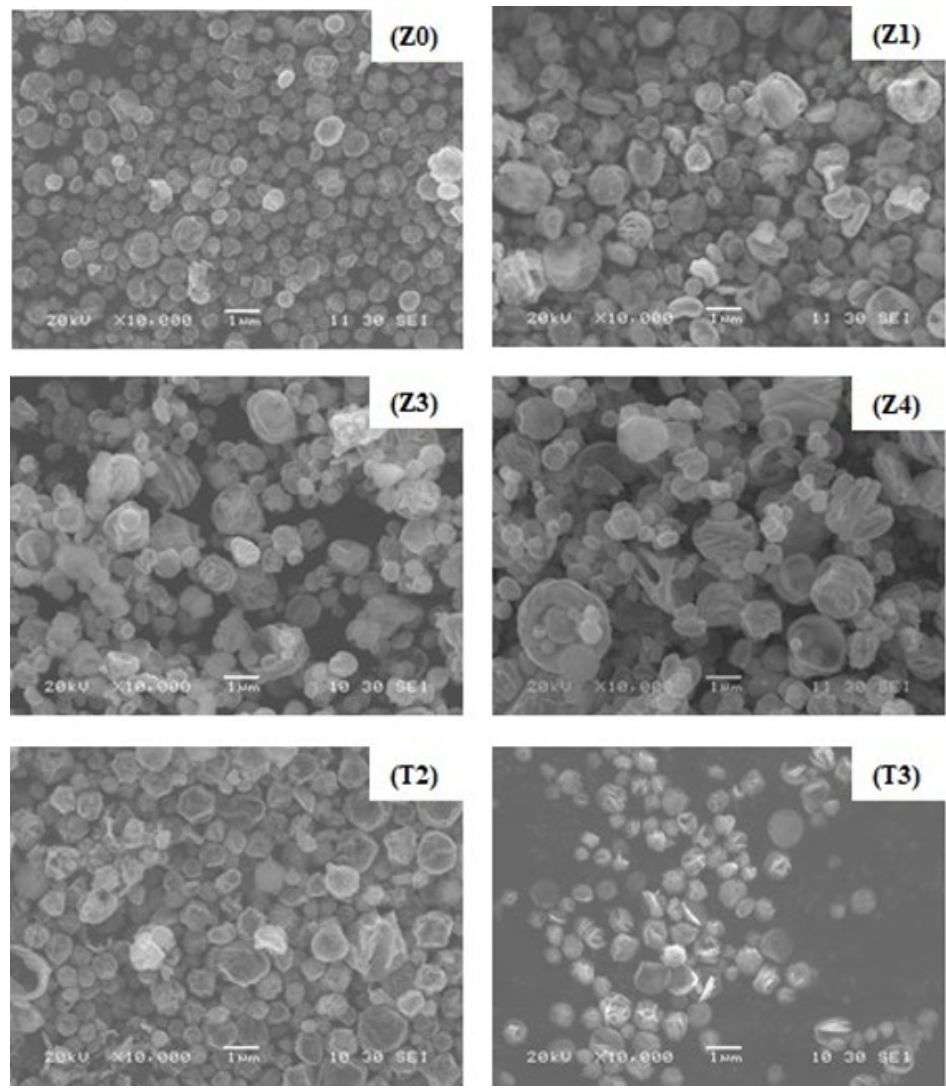
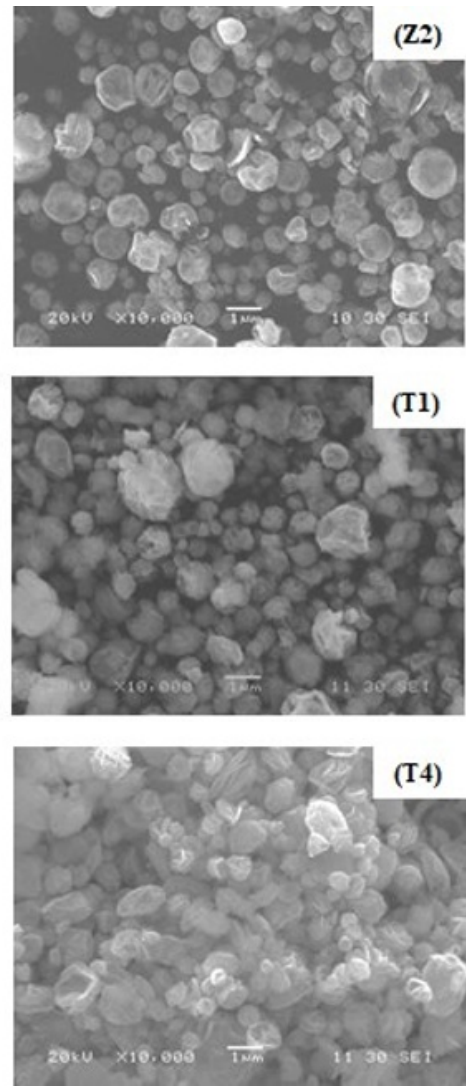

Figure 4. SEM images of $\mathrm{ZnO} / \mathrm{Au}$ particle obtained by USP synthesis 

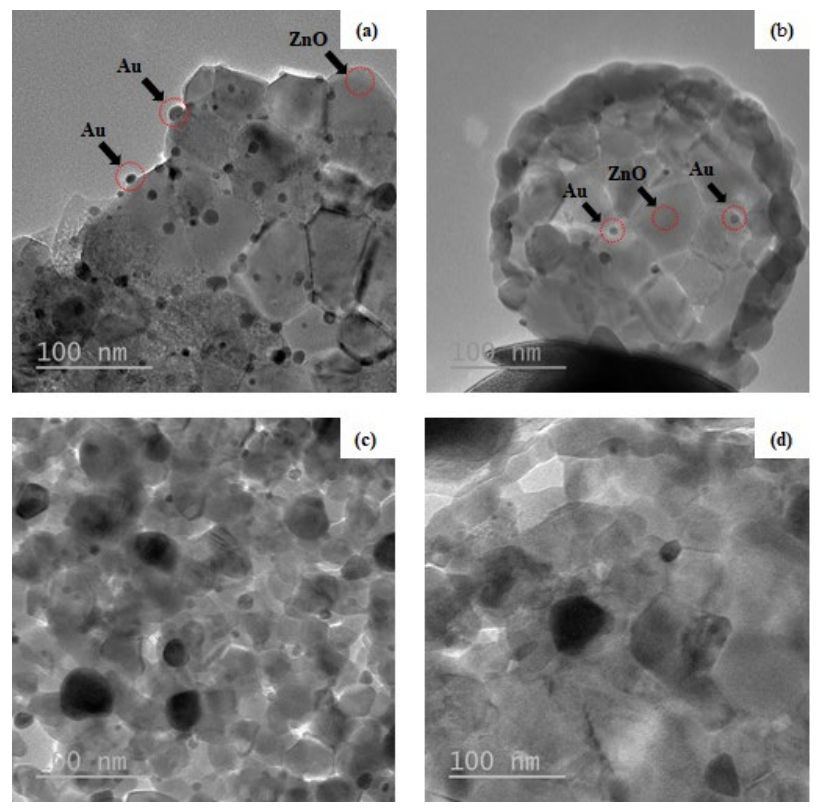

Figure 5. TEM images of $\mathrm{Au} / \mathrm{ZnO}$ particle obtained by USP synthesis: (a) Z2, (b) Z4, (c) T2, and (d) T4

where $\gamma$ is the surface tension of the solution, $f$ is the frequency of the ultrasonic transducer, and $\rho$ is the density of the solution.

Since the solution is very dilute, $\gamma$ and $\rho$ are estimated to be equal to the value of pure water. Assuming $\gamma=$ $0.0729 \mathrm{~N} / \mathrm{m}, \rho=1000 \mathrm{~kg} / \mathrm{m}^{3}$, and $f=1.7 \mathrm{MHz}$, the size of the droplet is calculated as $D_{\text {droplet }}=2.92 \mu \mathrm{m}$ from equation (1). If one particle is obtained from one aerosol particle, the average diameter of the generated $\mathrm{ZnO}$ particles can be calculated using the following equation

$$
D_{\mathrm{ZnO}}=\sqrt[3]{\frac{D_{\text {droplet }}^{3} C_{\mathrm{Zn}(\mathrm{NO})_{2 \mathrm{aq}}} M W_{\mathrm{ZnO}}}{M W_{\mathrm{Zn}(\mathrm{NO})_{2}} \rho_{\mathrm{ZnO}}}}
$$

where $D_{\mathrm{ZnO}}$ is $\mathrm{ZnO}$ particle diameter [m], $C_{\mathrm{Zn}(\mathrm{NO} \text { )2aq. is the }}$ raw material concentration $[\mathrm{g} / \mathrm{L}], M W_{\mathrm{ZnO}}$ is the molecular weight of $\mathrm{ZnO}(81.37 \mathrm{~kg} / \mathrm{kmol}), M W_{\mathrm{ZN}(\mathrm{NO} 3) 2}$ is the molecular weight of zinc nitrate $(297.49 \mathrm{~kg} / \mathrm{kmol})$, and $\rho_{\mathrm{ZnO}}$ is the density of $\mathrm{ZnO}\left(5.606 \times 10^{3} \mathrm{~kg} / \mathrm{m}^{3}\right)$. The estimated diameter of the generated particles is approximately $0.363 \mu \mathrm{m}$. The size of the particles observed in Figure $4(\mathrm{ZO})$ is between $0.3 \mu \mathrm{m}$ and $1.0 \mu \mathrm{m}$, confirming the existence of particles larger than the theoretical particle size.

The TEM images in Figure 5 can be supplemented with XRD and SEM. Figure 5 (a) shows that Au particles are distinguishable and nanometer-sized Au particles are dispersed in the surface of the $\mathrm{ZnO}$ particles. In the case of condition Z4, the crystal peak of Au in XRD is almost impossible to identify, but $\mathrm{Au}$ particles are observed in Figure 5 (b). Figures 5 (c) and (d) demonstrate that the size of the Au particle is larger with Triton X-100. This is consistent with the crystallite size calculated in Scherrer's equation.

\subsection{UV-Vis spectra}

Figures 6 and 7 show the UV-Vis absorption spectra of $\mathrm{ZnO} / \mathrm{Au}$ particles dispersed in water. The lower the concentration of chloroauric acid, the higher the visible light absorption peak near $400 \mathrm{~nm}$. This is attributed to resonance with high-energy light due to the increase in atomic vibrations caused by surface plasmons as the $\mathrm{Au}$ particle size changes. However, in the case of a high $\mathrm{Au}$ content, the amount of accumulated electrons in $\mathrm{Au}$ increases, and the recombination of electrons and holes is improved. Therefore, the particles obtained at a high content of chloroauric acid decrease the UV-Vis absorption spectrum. The observed $\mathrm{ZnO} / \mathrm{Au}$ particles are dark purple when the concentration of chloroauric acid is high but are light purple when the concentration of chloroauric acid is low.

To prevent $\mathrm{Au}$ particle aggregation, particles were produced in the same manner except Triton X-100 was added. The observed particles display a bluer tint compared to the case without Triton X-100. Adding Triton X-100 shifts the absorption peaks toward longer wavelengths and induces visible light absorption peaks at $450 \mathrm{~nm}$ and $650 \mathrm{~nm}$ (Figure 7). This means that the size of the Au particles generated by the addition of the Triton

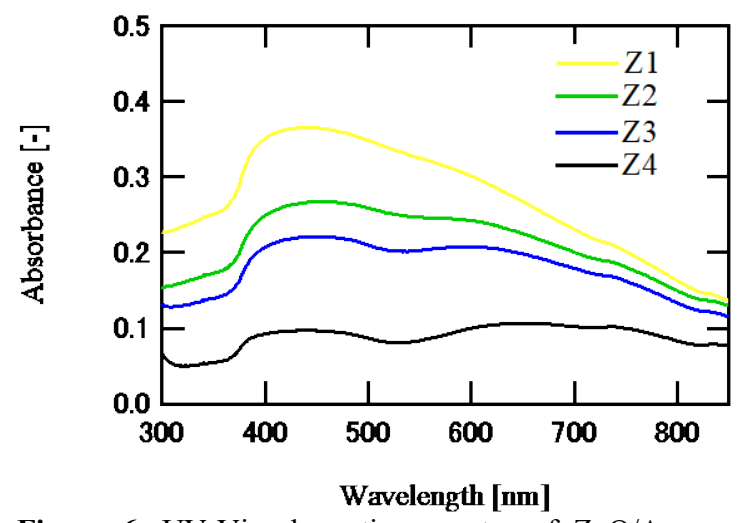

Figure 6. UV-Vis absorption spectra of $\mathrm{ZnO} / \mathrm{Au}$ particles prepared at different concentrations without Triton $\mathrm{X}-100$ 
$\mathrm{X}-100$ increases in the opposite direction, as confirmed by Scherrer's equation and the TEM image.

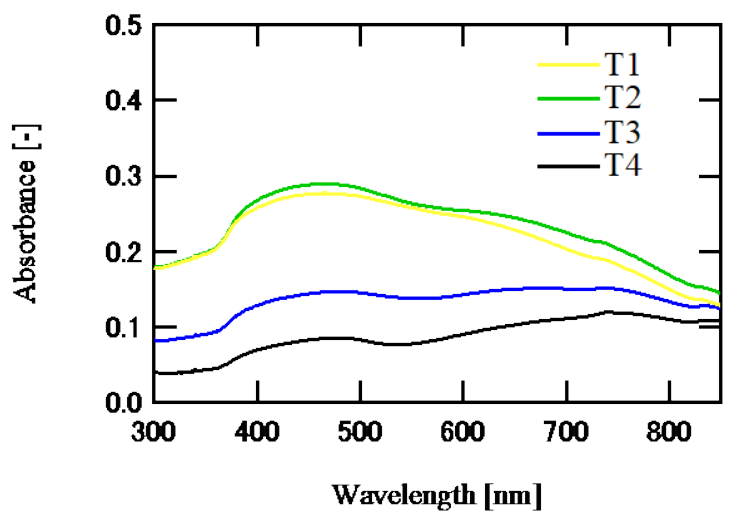

Figure 7. UV-Vis absorption spectra of $\mathrm{ZnO} / \mathrm{Au}$ particles prepared at different concentrations with Triton X-

\section{Conclusion}

In this study, $\mathrm{ZnO} / \mathrm{Au}$ particles with $\mathrm{Au}$ doped on $\mathrm{ZnO}$ are successfully generated by the ultrasonic spray pyrolysis method. In the XRD analysis of the particles generated using chloroauric acid and zinc nitrate as the raw material solution, peaks for both $\mathrm{Au}$ and $\mathrm{ZnO}$ are observed. Additionally, the TEM reveals that the Au particles are dispersed in the inner and outer portions of $\mathrm{ZnO}$. The absorbance and absorption of visible light increase when the concentration of chloroauric acid in the raw material solution is lowered.

Although Triton $\mathrm{X}-100$ is added to inhibit the agglomeration of $\mathrm{Au}$ particles, it promotes $\mathrm{Au}$ particle growth. This is related to the decomposition temperature and properties of Triton X-100. When the droplets of the raw material solution are heated in the preheating furnace and metal salt particles (zinc nitrate and chloroauric acid) precipitate, Triton X-100 forms micelles around the particles and acts as a dispersant. Triton $\mathrm{X}-100$ is not pyrolyzed in the process of reducing the water contained in the droplets. Triton X-100 has a decomposition temperature of $200^{\circ} \mathrm{C}$ or higher, but the electric furnaces (Nos. 1-3) used in this study are lower than $200^{\circ} \mathrm{C}$. Increasing the density of micelles in volume-reduced droplets promotes the aggregation of metal salt particles by the crosslinking action of linear polymers, increasing the crystal size of Au particles. That is, the collision of Triton X-100 with evaporation of the solvent in the droplets increases, forming rapid crosslinking between Triton X-100. Thus, fast crystal growth is achieved while increasing the crystal size.

\section{References}

Ardestani, M., M. Zakeri, M. J. Nayyeri, and M. R. Babollhaejie; "Synthesis of Ag-ZnO Composites via Ball Milling and Hot Pressing Processes," Mater. Sci-Poland, 32(1), 121-125 (2014)

Ebin, B., B. Ozkal, and S. Gurmen; "Production and Characterization of $\mathrm{ZnO}$ Nanoparticles and Porous
Particles by Ultrasonic Spray Pyrolysis Using a Zinc Nitrate Precursor," Int. J. Min. Met. Mater., 19, 651-656 (2012)

Fallah-Shojaei, A., K. Tabatabaeian, M. A. Zanjanchi, H. Fallah-Moafi, and N. Modirpanah; "Synthesis, Characterization and Study of Catalytic Activity of Silver Doped ZnO Nanocomposite as an Efficient Catalyst for Selective Oxidation of Benzyl Alcohol," J. Chem. Sci., 127, 481-491 (2015)

Feng, Y., J. Shen, X. Liu, Y. Zhao, X. Liang, J. Huang, J. Min, L. Wang, and W. Shi; "The Preparation and Optical Properties of $\mathrm{Ag}$ and $\mathrm{Ag} / \mathrm{ZnO}$ Composite Structure," J. Sol-Gel. Sci. Technol., 79, 98-106 (2016)

Fockedey, E. and A. Van Lierde; "Coupling of Anodic and Cathodic Reactions for Phenol Electro-oxidation Using Threedimensional Electrodes," Water Res., 36, 1469-4175 (2002)

Galindo, C., P. Jacques, and A. Kalt; "Photooxidation of the Phenylazonaphthol $\mathrm{AO} 20$ on $\mathrm{TiO}_{2}$ : Kinetic and Mechanistic Investigations," Chemosphere, 45, 997-1005 (2001)

Georgekutty, R., M. Seery, and S. C. Pillai; "A Highly Efficient Ag-ZnO Photocatalyst: Synthesis, Properties, and Mechanism," J. Phy. Chem. C, 112, 13563-13570 (2008)

Gouvea, C. A., F. Wypych, S. G. Moraes, N. Duran, N. Nagata, and P. Peralta Zamora; "Semiconductor-assisted Photocatalytic Degradation of Reactive Dyes in Aqueous Solution," Chemosphere, 40, 433-440 (2000)

Haes, A. J., D. A. Stuart, S. Nie, and R. P. Van Duyne; "Using Solution-Phase Nanoparticles, Surface-Confined Nanoparticle Arrays and Single Nanoparticles as Biological Sensing Platforms," J. Floresc., 14, 355-367 (2004)

Henglein, A; "Small-particle Research: Physicochemical Properties of Extremely Small Colloidal Metal and Semiconductor Particles," Chem. Rev., 89, 1861-1873 (1989)

Huang, T., X. Hong, and N. Xu; "Synthesis and Characterization of Tunable Rainbow Colored Colloidal Silver Nanoparticles Using Single-nanoparticle Plasmonic Microscopy and Spectroscopy," J. Mat. Chem., 20, 9867-9876 (2010)

Lang, R. J; "Ultrasonic Atomization of Liquids," $J$. Acoust. Soc. Am., 34, 6-9 (1962)

Mizutani, N., O. Sakurai, and T. Q. Liu; "Preparation of Spherical Fine ZnO Particles by the Spray Pyrolysis Method Using Ultrasonic Atomization Techniques," $J$. Mat. Sci., 21, 3698-3702 (1986)

Matthews, R. W.; "Photooxidative Degradation of Coloured Organics in Water Using Supported Catalysts. $\mathrm{TiO}_{2}$ on Sand," Water Res., 25, 1169-1176 (1991) 
Milosevic, O., D. Uskokovic, L. J. Karanovic, M. Tomasevic Canovic, and M. Trontelj; "Synthesis of ZnObased Varistor Precursor Powders by Means of the Reaction Spray Process," J. Mat. Sci., 28, 5211-5217 (1993)

Sauer, T., G. Cesconeto Neto, R. F. P. M. Moreira, and H. J. Jose; "Kinetics of Photocatalytic Degradation of Reactive Dyes in a $\mathrm{TiO}_{2}$ Slurry Reactor," J. Photochem. Photobiol. A, 149, 147-154 (2002)

Steigerwald, M. L. and L. E. Brus; "Semiconductor Crystallites: a Class of Large Molecules," Acc. Chem. Rev., 23, 183-188 (1990)

Wang, T., H. Wang, X. Zhao, Y. Liu, S. Chao, and P. Xu; "The Effect of Properties of Semiconductor Oxide Thin Films on Photocatalytic Decomposition of Dyeing Waste Water," Thin Solid Films, 334, 103-108 (1998)

Weller, H.; "Colloidal Semiconductor Q-Particles: Chemistry in the Transition Region Between Solid State and Molecules," Angew. Chem. Int. Ed., 32, 41-53 (1993)

Wuled, L., M, Lunden, and F. Iskandar; "An Experimental and Modeling Investigation of Particle Production by Spray Pyrolysis Using a Laminar Flow Aerosol Reactor," J. Mat. Res., 15, 733-743 (2000) 